\title{
INVESTIGAÇÃO DOS OBJETOS VIRTUAIS DE APRENDIZAGEM DEDICADOS A TEMÁTICA DE RESÍDUOS SÓLIDOS DISPONÍVEIS NO BANCO INTERNACIONAL DE OBJETOS EDUCACIONAIS (BIOE)
}

Thalyta Pessoa Freire, graduanda em Química na UACEN/CFP/UFCG, Thalytafreire1@gmail.com

Eriklys Darlan Gomes Bezerra, graduando em Química na UACEN/CFP/UFCG, eriklysdarlan@gmail.com

\section{RESUMO}

Os OVAs são elementos muito utilizados por alunos virtuais e são hospedados na rede mundial de computadores. O site do Banco Internacional de Objetos Educacionais dispõe de um acervo que inclui o tema "resíduos sólidos", objeto de estudo dessa pesquisa que analisou os OVAs sobre esse tema nesse banco, publicados entre 2008 e 2013, dedicados a alunos desde o ensino fundamental até o superior. A pesquisa foi feita online no site do banco e investigou 81 objetos. A maioria dos recursos tratam de reciclagem e reaproveitamento, mas os catadores também ganharam espaço, em contrapartida à PNRS, logística reversa e coleta seletiva, com poucos itens dedicados esses assuntos. A maioria também é direcionada ao nível fundamental, seguido do superior e, por último, o ensino médio, com grande parte publicados em 2011, após a sanção da PNRS, entretanto, o número de objetos publicados nos anos seguintes caiu severamente. Os tipos imagem e vídeo se sobressaem sobre os demais. Com isso, procura-se que o número de objetos hospedados no site aumente, que a busca seja mais específica e que ajudem ao estudante na compreensão e atualização dos conteúdos.

PALAVRAS-CHAVE: OVA; resíduos sólidos; BIOE.

\section{RESEARCH OF VIRTUAL LEARNING OBJECTS}

\section{DEDICATED TO THE THEME OF SOLID WASTE AVAILABLE IN THE INTERNATIONAL BANK OF EDUCATIONAL OBJECTS (BIOE)}

\section{ABSTRACT}

OVAs are elements widely used by virtual students and are hosted on the world wide web. The website of the International Bank of Educational Objects has a collection that includes the theme "solid waste", object of study of this research that analyzed OVAs on this subject in this bank, published between 2008 and 2013, dedicated to students from elementary school to graduation. The survey was conducted online at the bank's website and investigated 81 objects. The majority of the resources deal with recycling and reuse, but the garbage collectors also gained space, in contrast to the PNRS, reverse logistics and selective collection, with few items dedicated to these subjects. Most are also targeted at the fundamental level, followed by the upper level, and lastly, high school, with much 
published in 2011, after the sanctioning of the PNRS, however, the number of objects published in the following years fell severely. The image and video types stand out from the rest. With this, it is tried that the number of objects hosted in the site increases, that the search is more specific and that they help to the student in the understanding and update of the contents.

\section{INVESTIGACIÓN DE LOS OBJETOS VIRTUALES DE APRENDIZAJE DEDICADOS A TEMÁTICA DE RESIDUOS SÓLIDOS DISPONIBLES EN EL BANCO INTERNACIONAL DE OBJETOS EDUCACIONALES (BIOE)} RESUMEN

Los OVAs son elementos ampliamente utilizados por los estudiantes virtuales y están alojados en la Internet. El sitio web del Banco Internacional de Objetos Educativos tiene una colección que incluye el tema "Residuos Sólidos", objeto de estudio de esta investigación que analizó OVAs sobre este tema en este banco, publicado entre 2008 y 2013, dedicado a estudiantes de enseñanza fundamental a graduación. La encuesta se realizó en línea en el sitio web del banco e investigó 81 objetos. La mayoría de los recursos se ocupan del reciclaje y la reutilización, pero los recolectores de basura también ganaron espacio, en contraste con el PNRS, la logística inversa y la recolección selectiva, con pocos artículos dedicados a estos temas. La mayoría también están dirigidos al nivel fundamental, seguido por el nivel superior, y por último, la escuela secundaria, con mucho publicado en 2011, después de la sanción del PNRS, sin embargo, el número de objetos publicados en los años siguientes cayó gravemente. Los tipos de imagen y video se destacan del resto. Con esto, se intenta que el número de objetos alojados en el sitio se incremente, que la búsqueda sea más específica y que ayude al alumno en la comprensión y actualización de los contenidos.

PALABRAS CLAVES: OVA; residuos sólidos; BIOE

\section{INTRODUÇÃO}

As cidades abrigam mais da metade da população do mundo e estão crescendo muito rápido. De acordo com a Organização das Nações Unidas (ONU), cinco bilhões de pessoas morarão na zona urbana até 2030. Em virtude de dados e estimativas como esses, há uma crescente discussão sobre a urbanização, envolvendo a gestão de pessoas e recursos, e a construção de cidades sustentáveis.

A produção de lixo urbano é um assunto recorrente nas conferências mundiais e regionais. Nesse contexto, os resíduos sólidos são um dos temas mais recorrentes pela sua 
grande capacidade de poluir o solo, a água e o ar, diminuindo a sua qualidade e desequilibrando os ecossistemas. Governos e entidades públicas e particulares, associados ou de forma individual, tentam amenizar essa degradação, através de políticas públicas e iniciativas particulares.

Várias prefeituras do mundo têm criado um plano de desenvolvimento de cidade circular, onde os resíduos funcionam como recursos, de maneira sustentável. No entanto, a viabilidade desses planos só conseguida após frequentes discursos na gestão de pessoas e recursos, criando empregos e municípios que funcionam de forma inteligente.

A educação ambiental é um caminho conveniente para a concretização dessas medidas e prevenção de futuros problemas ao ambiente. Por isso, deve permear todos os componentes curriculares da educação escolar, além do apoio da família e de outras instituições sociais. Para facilitar o processo de ensino-aprendizagem, os Objetos Virtuais de Aprendizagem (OVAs) estão difundidos por toda a rede de computadores mundiais, uma vez que, através de imagens, simulações e vídeos, auxiliam da compreensão de materiais, padrões e processos da Natureza.

Diante do exposto acima, a pesquisa teve como objetivo analisar as características, problemáticas e contribuições dos OVAs dedicados às temáticas a respeito de "resíduos sólidos" de caráter interdisciplinar entre o Ensino Fundamental I e o Ensino Superior.

\section{REVISÃO DA LITERATURA}

\subsection{OBJETOS VIRTUAIS DE APRENDIZAGEM (OVAS)}

Com a evolução dos computadores, as maneiras de ensinar se modificaram, evoluindo para um patamar onde a interação aluno professor é mais dinâmica e, assim, constituindo uma importante ferramenta (BARÃO, 2006). O desenvolvimento dos computadores pessoais, entre 1970 e 1980, e a popularização da rede de comunicação mundial nas décadas seguintes, constituiu-se "como importante meio de divulgação acadêmica e cientifica, pela qual, alunos e professores podem se informar e se atualizar" (BARÃO, 2006, p. 4).

A aplicação das Tecnologias da Informação e Comunicação (TICs) na educação proporcionou um novo olhar sobre metodologias de ensino, pois quando utilizado como 
suporte pelos profissionais da educação torna o ensino rico e diversificado, contribuindo na construção do conhecimento pelo educando (FIGUEIREDO et al., 2016). Para Galafassi, Gluz e Galafassi (2013, p. 44), as TICs "passaram as serem vistos como tecnologias essenciais para a condução dos processos educacionais". Inseridos dentro destas estão os OVAs, no qual dão suporte ao professor no processo de ensino-aprendizagem, tornando coerente e, ao mesmo tempo, trazendo um maior significado aos conteúdos digitais.

Os OVAs são considerados uma tecnologia recente, onde não há uma concordância sobre sua definição, mas existe na literatura um entendimento que para ser classificado um OVA devem apresentar a característica da reutilização, ou seja, possibilitar a fragmentação do conteúdo em unidades semânticas que possam ser reutilizados em diferentes contextos (FIGUEREIDO et al, 2016).

É importante ressalvar que existe uma diferença entre Objetos Educacionais (OE) e Objetos de Aprendizagem (OA), onde, para Schwarzelmüller e Ornellas (2006), o primeiro constitui qualquer recurso capaz de apoiar no processo de ensino-aprendizagem, ou seja, qualquer conteúdo disponível na rede de comunicação mundial pode ser considerado um $\mathrm{OE}$, incluindo softwares que não possuem tal finalidade. Já o segundo, pela definição de Spinelle (2007, p. 7), seria "um recurso digital reutilizável que auxilie na aprendizagem de algum conceito".

Braga e Menezes (2014, p. 21) apontam algumas definições diferenciadas para denominar os Objetos de Aprendizagem (OA), por exemplo, a definição do Comitê de Padrões para a Tecnologia (Learning Technology Standards Committee - LTSC) do Instituto de Engenheiros Eletrônicos e Eletricistas (Institute of Electrical and Electronic Engineers IEEE): "qualquer entidade digital ou não, que pode ser usada, reutilizada ou referenciada durante o aprendizado apoiado pela tecnologia”. Essencialmente elas utilizam-se da definição apontada por David Wiley (2000), como "qualquer recurso digital que possa ser reutilizada para apoiar a aprendizagem" (apud BRAGA e MENEZES, 2014, p. 21), porém consideram que tal definição é abrangente, assim restringem essa a "aqueles que podem interferir diretamente na aprendizagem" (BRAGA e MENEZES, 2014, p. 22), sendo assim imagens, vídeos, animações, simulações e outras podem ser consideradas OA.

No Brasil e no mundo existem diversos repositórios que disponibilizam, gratuitamente, OVAs, entre um deles destacamos o Banco Internacional de Objetos 
Educacionais (BIOE), que surgiu da parceria, no ano de 2008, entre o Ministério da Educação (MEC), Rede Latino-Americana de Portais Educacionais (RELPE), Organização dos Estados Ibero-americanos (OEI), e o Ministério da Ciência e Tecnologia (MCT) (FIGUEREIDO et al., 2016). Para Silva e Salviano (2015, apud FIGUEREIDO et al., 2016, p. 3 ) "Neste repositório existem objetos de diferentes países e línguas, permitindo a qualquer professor, de qualquer parte do mundo, acessar, utilizar e submeter os recursos em sua língua materna, publicando as suas produções em um processo colaborativo".

\subsection{RESÍDUOS SÓLIDOS URBANOS (RSUS)}

Em 02 de agosto de 2010, foi sancionada a Lei $n^{\circ}$ 12.305, nomeada Política Nacional dos Resíduos Sólidos (PNRS). Segundo ela, pode-se definir resíduo sólido como qualquer

"[...] material, substância, objeto ou bem descartado resultante de atividades humanas em sociedade, a cuja destinação final se procede, se propõe proceder ou se está obrigado a proceder, nos estados sólido ou semissólido, bem como gases contidos em recipientes e líquidos cujas particularidades tornem inviável o seu lançamento na rede pública de esgotos ou em corpos d'água, ou exijam para isso soluções técnica ou economicamente inviáveis em face da melhor tecnologia disponível" (BRASIL, 2010).

A definição de Resíduo Sólido Urbano (RSU) é difícil de ser feita devido a vários fatores, como sua origem e formação. Portanto, trata-se como RSU todo material resultante da ação humana nas zonas urbanas e que é encaminhado sob responsabilidade do poder público para destinos considerados por ele adequados (LIMA, 2003). Esses resíduos podem ter origem a partir de seres vivos (animal ou vegetal, como restos de alimento, de pescados, casca de ovo), os chamados orgânicos, ou não, inorgânicos (ALBUQUERQUE NETO et al., 2007).

Uma das principais medidas dessa política era a extinção de todos os lixões do Brasil quatro anos após a sanção dessa lei. Entretanto, esse objetivo não foi atingido e, hoje, 3.334 municípios do país (60\%) ainda não destinam seus resíduos ao aterro sanitário, destino considerado adequado para o lixo urbano. As estimativas ficam ainda mais alarmantes quando se fala em quantidade de lixo per capta, pois, cada brasileiro produz pouco mais de um quilo de resíduos sólidos por dia (FRANÇA, 2017).

Entre os anos de 2014 e 2015, o crescimento do Produto Interno Bruto do Brasil (PIB) caiu 3,8\%, mas a produção de lixo aumentou de 78,6 milhões de toneladas para 79,9, quando se esperava que esses números também diminuíssem. Desses, 30 milhões ainda terminam nos 
lixões, local onde não há nenhum tratamento. O Projeto de Lei 2.289, de 08 de julho de 2015, que já foi aprovado no Senado e aguarda votação na Câmara, prevê a extensão do prazo citado acima até 2021 (FRANÇA, 2017).

O Panorama dos Resíduos Sólidos no Brasil 2015, da Abrelpe, afirma que a disposição final do lixo ainda está longe do ideal, visto que 1.552 prefeituras ainda não iniciaram o processo de transformação dos lixões em aterros sanitários, enquanto 1.774 despejam seus rejeitos em aterros controlados. As regiões Norte e Nordeste contribuem significativamente para esses números alegando que os seus governos não dispõem de capacidade técnica instalada e arrecadação suficientes para cumprir a lei (ABRELPE, 2015).

Podemos diferenciar o lixão como um local a céu aberto, onde os resíduos são despejados sem nenhum controle, produzindo gás metano $\left(\mathrm{CH}_{4}\right)$ pela decomposição de lixo orgânico, um dos que mais intensificam o aquecimento global, e chorume, líquido altamente poluente dos solos e lençóis freáticos, comprometendo a saúde pública. O aterro controlado é um intermediário ao lixão e ao aterro sanitário, que recebe uma cobertura de terra. Já o aterro sanitário possui um sistema de captação de líquidos e gases e, por isso, é considerado o destino ideal para o lixo urbano. Os aterros demandam de uma infraestrutura que conta com uma estação de tratamento, onde o material coletado (chorume e $\mathrm{CH}_{4}$ ) são transformados em créditos de carbono (FEAM, 2006).

Além do metano e do chorume, os resíduos sólidos podem causar outros danos ao ambiente, como a contaminação dos solos e das águas superficiais e profundos, proliferação de vetores de doenças, como insetos e roedores. O material particulado - minúsculas partículas de substâncias, como cinzas, que permanecem em suspensão no ar - diminuem a sua qualidade (OLIVEIRA, 2017).

Outro grande problema do descarte desses resíduos é a saúde pública, pois os riscos não são restritos às pessoas que entram em contato direto com eles, como os catadores, que relatam o convívio permanente com gripes e resfriados, dores musculares, problemas osteoarticulares e dermatológicos, dengues, verminoses, alergias, conjuntivite, cortes com agulhas, perfurações e contusões. Um problema que ainda não tem uma resolução definitiva a nível nacional é o descarte de materiais com metais pesados (lâmpadas de mercúrio, por exemplo) e o lixo radioativo (BORGES, 2014). 
A gestão dos resíduos sólidos é também uma questão socioeconômica, pois o lixo é fonte de renda para muitas famílias no Brasil que atuam de forma independente ou em associações de catadores. O catador é o protagonista da coleta seletiva, porém essa ação é insuficiente no Brasil, onde apenas 3\% do lixo é reciclado. De acordo com a Pesquisa Nacional por Amostra de Domicílios (PNAD), de 2006, existia um total de 230.000 catadores no país, porém a quantidade real e atual é desconhecida, fala-se num valor entre 500.000 e 1 milhão (PAIVA, 2015).

Assim, é necessário distinguir os resíduos dos rejeitos. O primeiro é considerado o material capaz de ser consertado, servir para outra finalidade ou ser reciclado, já o segundo é o produto que se esgotou o seu ciclo de vida e não há possibilidade nenhuma de reaproveitamento ou reciclagem. Considera-se reciclagem o processo em que um objeto é transformado em outro material e reaproveitamento a utilização desse mesmo material para mesma finalidade ou com uma finalidade diferente (ETHOS, 2012).

Um outro destino dado aos resíduos é a incineração, uma prática que necessita de uma infraestrutura e um alto custo para a operação. Define-se incineração nesse caso como o processo para redução do peso, do volume (90\%) e de características patogênicas (bactérias e vírus, por exemplo), pela combustão controlada, que libera energia para vapor ou eletricidade. Entretanto, exige uma mão de obra qualificada e não é tão simples quanto parece, considerando as diferentes características das categorias do lixo urbano (NASCIMENTO et al., 2000).

\section{METODOLOGIA}

A escolha do tema desta pesquisa se deu a partir de dois estudos bibliográficos conceituais desenvolvidos como parte estruturante do presente artigo. Um ligado ao contexto dos avanços tecnológicos e desafios emergentes da necessidade de responder às demandas da sociedade da informação e os chamados "alunos digitais" e um segundo elucidando a questão dos resíduos, particularmente dos resíduos sólidos, como elemento fundamental da crise ambiental na atualidade. Para alcançar o objetivo, realizou-se uma investigação acerca dos Objetos Virtuais de Aprendizagem (OVAs) para o ensino de ciências tendo como temática os resíduos sólidos. 
A pesquisa foi feita online, através do site <http://objetoseducacionais2.mec.gov.br/>, de acesso livre e gratuito, do repositório BIOE (Banco Internacional de Objetos Educacionais). O acesso foi realizado entre os dias 04 e 19 de agosto de 2017. A "busca por objetos" utilizou a palavra-chave "resíduos sólidos" e não incluiu especificação para os campos "País", "Idioma" e "Tipo de recurso", sendo assim, 07 (sete) dos objetos explorados estão no Idioma Espanhol (es) e País Colômbia (co).

Figura 1: Tela de início do BIOE.

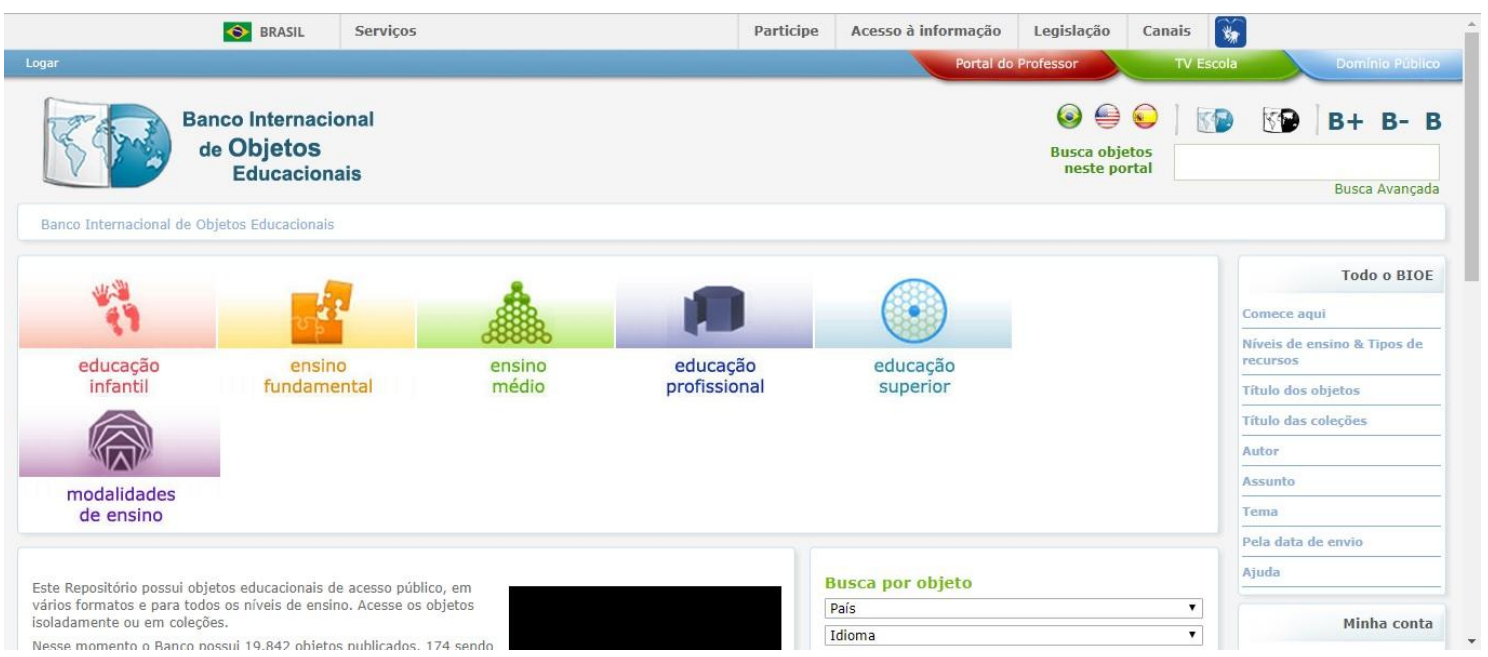

Fonte: BIOE. Acesso em: 19 de agosto de 2017.

Para o desenvolvimento dessa pesquisa foram analisados 81 objetos disponíveis de acordo com os comandos de busca citados acima.

Figura 2: Resultados da busca por Objetos Virtuais de Aprendizagem sobre a temática "Resíduos Sólidos" no BIOE.

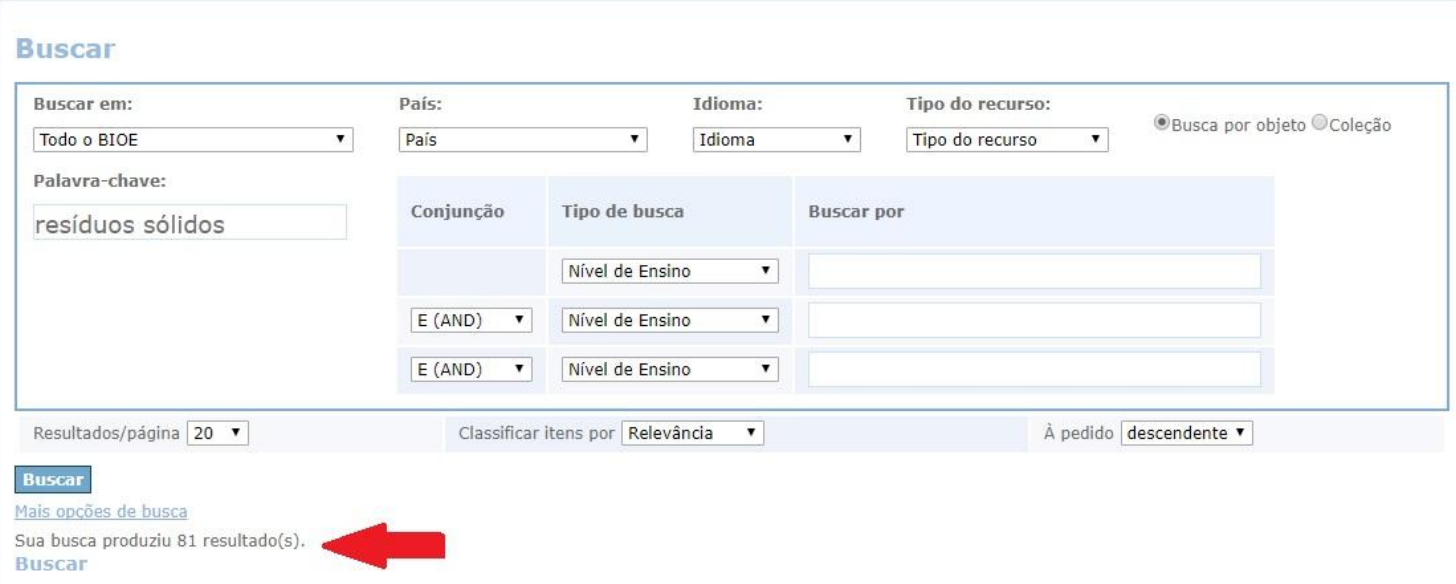

Fonte: BIOE. Acesso em: 19 de agosto de 2017.

Os critérios quantitativos para a investigação dos objetos foram: 
- Tema: conceitos desenvolvidos no objeto;

- Nível de Ensino: público alvo do recurso, podendo ser alunos do Ensino Fundamental (Inicial I/ Final II), Ensino Médio e Ensino Supeior;

- Tipo de recurso: espécie de multimídia utilizada;

- Ano de publicação: data em que o objeto foi hospedado no site.

Quanto ao tema, os OVAs foram categorizados em dez classes: "Aterro Sanitário", "Catadores", "Coleta Seletiva", "Destino Final dos Resíduos Sólidos", "Educação Ambiental", "Impactos ao Ambiente", "Incineração", "Logística Reversa", "PNRS", "Reciclagem e Reaproveitamento" e "Restauração Ambiental". Os objetos são direcionados a alunos do nível de ensino fundamental ao superior, publicados entre 2008 e 2013 e diferenciam-se em seis tipos, animação/simulação, experimento prático, imagem, software educacional e vídeo. Ao final, os resultados foram colocados em tabelas a fim de facilitar a observação das quantidades, buscando entender os valores nelas contidos.

\section{RESULTADOS E DISCUSSÃO}

\subsection{EM RELAÇÃO AO TEMA}

Tabela 1: Quantidade de OVA sobre resíduos sólidos disponíveis no BIOE classificado por unidades temáticas.

\begin{tabular}{lc}
\hline \multicolumn{1}{c}{ TEMA } & QUANTIDADE \\
\hline Aterro Sanitário & 06 \\
Catadores & 10 \\
Coleta Seletiva & 03 \\
Destino Final dos Resíduos Sólidos & 07 \\
Educação Ambiental & 05 \\
Impactos ao Ambiente & 07 \\
Incineração & 02 \\
Logística Reversa & 01 \\
PNRS & 01 \\
Reciclagem e Reaproveitamento & 41 \\
Restauração Ambiental & 07 \\
\hline \multicolumn{2}{r}{ TOTAL } \\
\hline
\end{tabular}

Fonte: Próprios autores, 2017.

Alguns OVAs coincidiram por tratar de mais de um tema, por isso, a soma de todas as quantidades (90) excede o número de objetos (81). Em relação a “Aterro Sanitário”, os seis 
objetos descrevem o que é o aterro, os seus benefícios, porque este é o destino mais adequado, a sua infraestrutura, como acontecem os processos de transformação do lixo em energia e um estudo de caso de um aterro sanitário da cidade de Belo Horizonte (MG). Quanto aos "Catadores", os 10 objetos retratam a sua importância, como trabalham individualmente ou em cooperativas, a sua problemática social e econômica e os processos de triagem.

O tema "Coleta Seletiva" tem um acervo insatisfatório, visto que apenas três objetos foram encontrados, ressaltando apenas o modo como à coleta é feita e que tipos de materiais são recolhidos. O "Destino Final dos Resíduos Sólidos" (sete objetos) retrata a ineficiência dos lixões na gestão dos rejeitos e como deve ser feito o seu tratamento e os seus impactos de forma breve. Cinco objetos apresentam iniciativas para "Educação Ambiental", principalmente no sentido de reduzir o lixo doméstico e bioconsciência.

Os OVAs do Banco Internacional de Objetos de Aprendizagem também enumeram alguns "Impactos ao Ambiente" (sete itens) - chuva ácida, contaminação dos solos e da água, proliferação de microrganismos (ameba) - de forma direta e indireta, com algumas alternativas para diminuir os desequilíbrios ambientais. Dois arquivos falam de "Incineração", mostrando como esse processo é feito e a infraestrutura necessária. Um arquivo também retrata a "Logística Reversa", entretanto de forma insuficiente, e um a PNRS, ressaltando a proibição dos lixões até 2014 e o fracasso dessa meta.

O tema "Reciclagem e Reaproveitamento" é o que mais aparece na análise, foram 41 OVAs discutindo esse assunto. Entre os materiais a serem a reciclados e reaproveitados estão baterias, entulhos de materiais de construção, pilhas, plásticos, garrafas PET, pneus, restos orgânicos, sacolas plásticas e vidros. Por último, "Restauração Ambiental" reúne 07 itens sobre o tratamento de efluentes.

\subsection{EM RELAÇÃO AO NÍVEL DE ENSINO}

Nesse critério, também coincidiu de um mesmo objeto atender a mais de uma classe, por isso a quantidade total (85) está acima do número de objetos analisados. Observou-se que o nível com maior quantidade de objetos foi o nível fundamental (I e II) enquanto o médio possui o menor. 
Tabela 2: Quantidades de OVA sobre resíduos sólidos disponíveis no BIOE de acordo com o nível de ensino.

\begin{tabular}{cc}
\hline \multicolumn{1}{c}{ NÍVEL } & QUANTIDADE \\
\hline Ensino Fundamental & 39 \\
Ensino Médio & 14 \\
Ensino Superior & 32 \\
\hline TOTAL & 85 \\
\hline
\end{tabular}

Fonte: Próprios autores, 2017.

Esperava-se uma maior incidência de objetos para atender ao Ensino Médio, pois esse discurso ganha maior visibilidade nesse nível de ensino, com abordagem em todas as disciplinas, numa perspectiva transversal, como proposto pelo Ministério da Educação (MEC) em comparação com o nível fundamental.

\subsection{EM RELAÇÃO AO ANO}

Tabela 3: OVA disponíveis no BIOE de acordo com o ano de publicação.

\begin{tabular}{cc}
\hline ANO DE & QUANT \\
PUBLICAÇÃO & IDADE \\
\hline 2008 & 02 \\
2009 & 08 \\
2010 & 06 \\
2011 & 58 \\
2012 & 01 \\
2013 & 06 \\
\hline TOTAL & 81 \\
\hline
\end{tabular}

Fonte: Próprios autores, 2017.

Percebeu-se que o ano em que mais se publicaram OVAs no Banco Internacional de Objetos Educacionais foi 2011. Nos anos de 2008 e 2012, o número de objetos publicados foi bastante baixo, 02 e 01 respectivamente.

Em 2010 aconteceu uma revolução da politica ambiental do Brasil com a PNRS, o que pode justificar o maior número de publicações em 2011, com a intenção de divulgar, educar e iniciar as medidas impostas nessa por essa lei. Entretanto, no ano seguinte (2012) apenas uma publicação foi feita, valor quase desprezível, quando se percebe o contexto ambiental nos anos anteriores. Em 2013, esse fato quase se repetiu, com apenas seis publicações.

\subsection{EM RELAÇÃO AO TIPO DE RECURSO}


Tabela 4: OVA sobre resíduos sólidos disponíveis no BIOE de acordo com o tipo de recurso.

\begin{tabular}{lc}
\hline TIPO DE RECURSOS & QUANTIDADE \\
\hline Animação/Simulação & 02 \\
Experimento Prático & 03 \\
Imagem & 42 \\
Software educacional & 01 \\
Vídeo & 33 \\
\hline \multicolumn{1}{c}{ TOTAL } & 81 \\
\hline
\end{tabular}

Fonte: Próprios autores, 2017.

A categoria "Imagem" apresentou o maior número (42), enquanto "Software educacional" o menor (01). "Animação/Simulação" e "Experimento Prático" também mostraram números muito baixos, 02 e 03 , respectivamente. Sete dos objetos estão no idioma espanhol, sem legenda em português, o que dificulta a sua compreensão, pois todos são vídeos.

\section{CONCLUSÃO}

O acúmulo de resíduos sólidos em lixões sem nenhum tratamento ou aproveitamento tem tirado o sossego da sociedade que a cada dia lida com os problemas ocasionados por essa prática. Na tentativa de gerenciar esse transtorno, governos e entidades particulares têm investido na educação ambiental por meio de metodologias mais ativas. A hospedagem de OVAs na rede mundial de computadores é uma das alternativas na compreensão de padrões e processos e o Banco Internacional de Objetos Educacionais um dos sites mais populares na difusão desses objetos.

A pesquisa concluiu que um grande número de objetos foi publicado no ano de 2011 , após a publicação da Lei 12.305/2010 (PNRS), entretanto, no ano seguinte esse número se reduziu a praticamente zero. Curiosamente, uma das principais metas dessa política fracassou, a eliminação dos lixões no Brasil.

Nesse sentido, deseja-se que o número de objetos hospedados no site aumente à medida que alternativas para reduzir o impacto dos resíduos sólidos sejam propostas, que a busca seja mais específica, como a separação dos resultados em categorias e que ajudem ao estudante na compreensão e atualização dos conteúdos. 


\section{REFERÊNCIAS}

ABRELPE. Panorama dos Resíduos Sólidos no Brasil 2015. São Paulo, 2015.

ALBUQUERQUE NETO, H. C. et al. Caracterização de resíduos sólidos orgânicos produzidos no restaurante universitário de uma instituição pública (estudo de caso). In: Encontro Nacional de Engenharia de Produção, 27, 2007, Foz do Iguaçu. Anais eletrônicos... Foz do Iguaçu: 2007. Disponível em: $\langle$ http://www.abepro.org.br/biblioteca/enegep2007_tr650481_0422.pdf $>$. Acesso em: 08 ago. 2017.

BARÃO, G. C. Ensino de Química em ambientes virtuais. In: PARANÁ. Secretaria de Estado da Educação. Superintendência de Educação. O professor PDE e os desafios da escola pública paranaense, 2007. Curitiba: SEED/PR., 2011. v.1. (Cadernos PDE). Disponível em: <http://www.gestaoescolar.diaadia.pr.gov.br/modules/conteudo/conteudo.php?conteudo=20> Acesso em 12 jan. 2017.

BORGES, W. Lixo acumulado a céu aberto pode causar doenças à população do Rio. Disponível em: <https://oglobo.globo.com/rio/lixo-acumulado-ceu-aberto-pode-causardoencas-populacao-do-rio-11798416> . Acesso em: 15 ago. 2017.

BRAGA, J.; MENEZES, L. Introdução aos Objetos de Aprendizagem. In: BRAGA, J. (org.). Objetos de Aprendizagem: Introdução e fundamentos. Santo André: Editora da UFABC, 2014. $148 \mathrm{p}$.

BRASIL. Lei 12.305, de 02 de agosto de 2010. Publicada no Diário Oficial da União em 03 de agosto de 2010.

ETHOS. Política Nacional de Resíduos Sólidos: desafios e oportunidades para as empresas. Secretaria Executiva do Instituto ETHOS. São Paulo: 2012.

FIGUEIREDO, L. V. de et al. Objetos de aprendizagem disponibilizados pelo banco internacional de objetos educacionais para o ensino de química. In: III CONGRESSO NACIONAL DE EDUCAÇÃO, Vol. 1, 2016, Natal - RN. Anais... Natal: Editora Realize, 2016.

FEAM. Orientações básicas para operação de aterro sanitário. Belo Horizonte: FEAM, 2016.

FRANÇA, M. S. J. O destino do nosso lixo. In: PRADO, A. et al. Atualidades: vestibular + enem. São Paulo: Abril, 2017.

GALAFASSI, F. P.; GLUZ, J. C.; GALAFASSI, C. Análise crítica das pesquisas recentes sobre as tecnologias de objetos de aprendizagem e ambientes virtuais de aprendizagem. Revista Brasileira de Informática na Educação, v. 21, n. 3, p. 41-52, 2013. 
LIMA, J. S. Avaliação da contaminação do lençol freático do lixão do município de São Pedro da Aldeia - RJ. 2003. 87 p. Dissertação (Mestrado em Engenharia Ambiental) Universidade Federal do Rio de Janeiro, 2003.

NASCIMENTO, L. C. de A.; ALMEIDA FILHO, N. B. de; ZAKON, A. Cinzas da incineração de lixo: matéria-prima para cerâmicas. Ciência Hoje, Campinas v. 27, n. 160, p. 63-67, maio 2000.

OLIVEIRA, M. C. de. et al. Resíduos sólidos urbanos e impactos ambientais: legislação e educação ambiental. Âmbito Jurídico, Rio Grande, v. 20, n. 159, abr. 2017. Disponível em: $<$ http://www.ambitojuridico.com.br/site/?n_link=revista_artigos_leitura\&artigo_id=18751\&revista_caderno=5>. Acesso em 10 ago. 2017.

PAIVA, R. Apenas 3\% de todo o lixo produzido no Brasil é reciclado. Disponível em: $<$ http://g1.globo.com/jornal-hoje/noticia/2015/04/apenas-3-de-todo-o-lixo-produzido-nobrasil-e-reciclado.html>. Acesso em 15 ago. 2017.

SCHWARZELMÜLLER, A. F.; ORNELLAS, B. Os objetos digitais e suas utilizações no processo de ensino-aprendizagem. In: Primeira Conferencia Latinoamericana de Objetos de Aprendizaje. 2006. Disponível em: <http://www.bvs.hn/cu2007/ponencias/EDU/EDU022.pdf > Acesso em: 28 nov. 2016.

SPINELLI, W. Os objetos virtuais de aprendizagem: ação, criação e conhecimento.2007. Disponível em: <http://www.lapef.fe.usp.br/rived/textoscomplementares/textoImodulo5.pdf>. Acesso em:11 jan. 2016. 